\title{
BRONCHOSCOPIC TREATMENT OF ATELECTASIS IN CHILDREN
}

\author{
BY \\ B. GANS \\ From the Paediatric Department, Lewisham Hospital, London
}

(RECEIVED FOR PUBLICATION DECEMBER 3, 1951)

Pulmonary atelectasis in children was often found to have cleared soon after diagnostic bronchoscopy. Re-ventilation occurred even in children in whom the collapse had resisted the usual methods of treatment during preceding weeks or months. It was, therefore, decided to bronchoscope every child with pulmonary collapse provided the collapse was known to have existed for more than five weeks. In a few children the examination was carried out sooner than five weeks after the existence of the collapse was known, either because the indications were urgent or because the collapse could reasonably be assumed to have existed for a considerable time.

Bronchoscopy was carried out on $\mathbf{5 0}$ consecutive children admitted with atelectasis, unselected apart from the exclusion of cases due to foreign body, and irrespective of the presumed aetiology of the collapse. Sixty-seven collapsed lobes were present in these 50 children, whose ages ranged from 17 days to 12 years, the average age being 3 years 11 months. The lobes involved were: right upper, 14; right middle, 17; right lower, 21; left upper (including lingula), 7; left lower, 8. In 15 cases several lobes were collapsed. The collapse was known to have existed from three days to two years four months, the average being $15 \frac{1}{2}$ weeks.

Antero-posterior and lateral radiographs were taken 10 days after the examination. The effect of bronchoscopic aspiration was considered good if the lung had re-expanded after 10 days, fair if it had cleared one month after bronchoscopy and poor if the collapse persisted.

\section{Results}

Of the total of 67 collapsed lobes, $34(51 \%)$ cleared in 10 days, $13(19 \%)$ in a month, and 20 $(30 \%)$ failed to clear (Table 1$)$. It became obvious that in children with positive Mantoux reactions the collapse was less likely to clear than in those in whom the reaction was negative. The 21 children with a positive Mantoux reaction had 26 collapsed lobes. Of these, eight $(31 \%)$ had a ' good' result, five $(19 \%)$ a 'fair' result and in $13(50 \%)$ the result was 'poor' (Table 2). Of the
TABLE 1

Effect of Bronchoscopy on 67 Unselected Atelectatic Lobes

\begin{tabular}{|c|c|c|c|c|}
\hline Lobe & Good & Fair & Poor & Total \\
\hline R.U. & 5 & 2 & 7 & 14 \\
\hline R.M. & 8 & 3 & 6 & 17 \\
\hline R.L. & 13 & 6 & 2 & 21 \\
\hline L.U. & 4 & 0 & 3 & 7 \\
\hline L.L. & 4 & 2 & 2 & 8 \\
\hline Total & 34 & 13 & 20 & 67 \\
\hline
\end{tabular}

TABLE 2

EFtect of Bronchoscopy on 26 Atenectatic Lodes in ChILDREN With Promary Tuegrculous Comprex

\begin{tabular}{|c|c|c|c|c|}
\hline Lobe & Good & Fair & Poor & Total \\
\hline R.U. & 2 & 1 & 3 & 6 \\
\hline R.M. & 2 & 1 & 5 & 8 \\
\hline R.L. & 3 & 2 & 1 & 6 \\
\hline L.U. & 1 & 0 & 3 & 4 \\
\hline L.L. & 0 & 1 & 1 & 2 \\
\hline Total & 8 & 5 & 13 & 26 \\
\hline
\end{tabular}

29 children whose 41 collapsed lobes were not associated with a primary tuberculous complex, $26(63 \%)$ had a 'good' result, eight $(20 \%)$ a ' fair' result, and in seven $(17 \%)$ the result was 'poor' (Table 3).

TABU 3

Eprect of Beonchoscopy on 41 A tmectatic Lobes in ChILdenen Wimh Negative Mantoux Reactions

\begin{tabular}{|c|c|c|c|c|}
\hline Lobe & Good & Fair & Poor & Total \\
\hline R.U. & 3 & 1 & 4 & 8 \\
\hline R.M. & 6 & 2 & 1 & 9 \\
\hline R.L. & 10 & 4 & 1 & 15 \\
\hline L.U. & 3 & 0 & 0 & 3 \\
\hline LL & 4 & 1 & 1 & 6 \\
\hline Total & 26 & 8 & 7 & 41 \\
\hline
\end{tabular}

\section{Bronchoscopic Findings}

The difference in the response of Mantoux positive and Mantoux negative children is not surprising. It is well known that the atelectasis commonly found in primary tuberculous infection 
(' epituberculosis') is due to enlarged glands pressing on a bronchus from without (Jones, Rafferty and Willis, 1942), leading first to narrowing and later to occlusion of the bronchial lumen, with absorption collapse behind the block.

In these circumstances the introduction of a sucker into the bronchus behind the obstruction cannot be expected to lead to re-aeration of the collapsed segment as the obstruction is not removed. In several instances, however, bronchoscopy had a good effect. In three cases rupture of a tuberculous gland had led to extreme, sudden dyspnoea, associated with cyanosis, pallor and shock. Removal of glandular debris and caseous material resulted in re-ventilation of the collapsed lobe or lobes, and may have been of life-saving importance (GörgényiGöttche and Kassay, 1947). In several other cases the lobe re-expanded after the removal of secretions from behind a stenosed part of the bronchus.

The bronchoscopic appearances in these children with tuberculous collapse were similar to those described by Hutchison (1949). In 13 an enlarged gland was seen to be pressing on one or more bronchial openings. In nine instances a velvety, injected mucosa, as described by Jackson and Jackson (1950), was found overlying the enlarged gland, and once a shallow uker was found. No local treatment by silver nitrate or dilation was considered necessary as the children with parenchymal infiltration or tuberculous bronchopneumonia were treated systemically with streptomycin or P.A.S. In six cases a bronchial swab revealed tubercle bacilli on direct smear or culture, though examination of stomach washings, material coughed upon a laryngeal mirror and stool examinations had repeatedly given negative results.

Of the 41 collapsed lobes not associated with a primary tuberculous complex, 16 were due to whooping cough, 11 to pneumonia, five to measles, three to massive collapse associated with empyema, three to atelectasis in bronchiectatic lobes, two were congenital and one was due to a persistent antral infection. Similar aetiological factors have been described by Oswald (1947). All cases of post-pertussis collapse had persisted for more than five weeks before they were bronchoscoped, and all had been treated with sulphonamides, antibiotics or postural drainage on one or more occasions without success. It was thought essential to delay bronchoscopy in these post-pertussis cases in view of Lees' (1950) finding that the majority of collapsed lobes had cleared by the fifth week.

In these non-tuberculous patients bronchoscopic aspiration led to re-ventilation of the collapsed lobes in $83 \%$ of cases within one month. In several instances no obstruction was seen, and even so the collapse cleared after bronchoscopy. It is possible that the hyperventilation and coughing occasionally associated with the anaesthetic may have led to clearance in these cases. On the other hand this unexplained clearance happened no more frequently in children in whom induction and recovery were stormy than in those anaesthetized by experts with pentothal and curare.

In 11 cases organisms were grown from a bronchial swab. The organisms found were Staph. aureus, $N$. catarrhalis, $H$. influenzae, pneumococci, Strep. pyogenes and diphtheroids. One neoplasm, not responsible for the atelectasis, was found, and the biopsy section report was of ' a small nodule of fibrous tissue consisting of spindleshaped cells enmeshed in a loose collagenous matrix. The appearance suggests that it is a small benign fibroma; it might be of neurofibromatous origin' (Dr. M. O. Skelton, Lewisham Group Laboratory).

\section{Technique}

The examinations were carried out with a Negus type of bronchoscope, introduced without a laryngoscope. Notwithstanding Chevalier Jackson's advice, all children were given a general anaesthetic as it was felt that psychic trauma might otherwise result. Also, the examination can be carried out much more quickly in an unconscious than in a struggling child. The anaesthetic used was usually pentothal and curare, but several examinations were carried out under trilene, nitrous oxide or ether anaesthesia. In no case did anaesthetic complications arise. It was found that the appearance of the trachea and carina was often markedly affected by the use of curare. The posterior tracheal wall was slack and bulged into the tracheal lumen, and similarly the carina was 'slacked off' so that its edge became blunt and shortened anteroposteriorly. In several cases the introduction of lipiodol was attempted, using a specially adapted sucker which was passed through the bronchoscope. Whilst individual lobes could be well filled, attempted filling of the whole side gave poor results because the child could not be positioned satisfactorily with the bronchoscope in situ.

There were no post-operative complications, and oil aspiration pneumonia due to lubrication of the bronchoscope with liquid paraffin (Brimblecombe, Crome and Tizard, 1951) did not occur. As the examination hardly ever lasted longer than 10 minutes local and general upset was negligible. There was no difference in the course of those children who had a penicillin cover for 24 hours before and 48 hours after bronchoscopy, and those who did not. 


\section{Discussion}

It has long been recognized that atelectasis either alone (Lander and Davidson, 1938) or in the presence of infection (Tannenberg and Pinner, 1942) is the precursor and main cause of bronchiectasis (Coryllos and Birnbaum, 1929; Anspach, 1934). The parts of the lung most commonly involved in atelectasis are the same as those most commonly affected by bronchiectasis (Lees, 1950). There is general agreement that the likelihood of bronchiectasis developing in an atelectatic lobe depends on the length of time the lobe remains collapsed (Nicholson, 1949). Clearly, therefore, the recognition and early and effective treatment of atelectasis in childhood are of the utmost importance if permanent bronchial dilatation is to be avoided.

Various methods of treatment have been used, such as inhalation of carbon dioxide, postural coughing and postural drainage, heavy percussion of the chest wall and breathing exercises. Many of these methods are difficult or impossible to carry out in children, and in any case they are unlikely to be successful if the collapse has persisted for any length of time (Ellis, 1933). On the other hand bronchoscopic aspiration of an obstructed bronchus is frequently effective in clearing a collapsed lobe, and has the additional advantage of allowing the cause of the collapse to be established in a large number of cases (Holinger, 1950).

\section{Summary}

Bronchoscopic aspiration in cases of atelectasis in children frequently leads to re-expansion of the collapsed lobe, and therefore prevents bronchiectasis. Results are better when the collapse is due to an acute infection, and less good if collapse results from pressure by glands on a bronchus. The general and local upset following bronchoscopy in children is slight.

I wish to express my thanks to Dr. H. S. Banks for his valuable advice and for referring some of the cases of post-pertussis collapse, also to Dr. J. M. Piney and Dr. W. S. Hart who gave many of the anaesthetics.

\section{REFERENCES}

Anspach, W. E. (1934). Amer. J. Dis. Child., 47, 1011

Brimblecombe, F. S. W., Crome, L and Tizard, J. P. M. (1951). Archives of Disease in Childhood, 26, 141.

Coryllos, P. N. and Birnbaum, G. L. (1929). Amer. J. Roentgenol., 22, 401 .

Ellis, R. W. B. (1933). Archives of Disease in Childhood, 8, 25

Görgényi-Göttche, O. and Kassay, D. (1947). Amer. J. Dis. Child., 74, 166.

Holinger, P. H. (1950). Reported in Amer. J. Dis. Child., 79, 1143. Hutchison, J. H. (1949). Qwart. J. Med., N.S. 18, 21.

Jackson, C. and Jackson, C. L. (1950). In ' Bronchoesophagology', Philadelphia.

Jones, E. M., Rafferty, T. N. and Willis, H. S. (1942). Amer. Rev. Tuberc. 46 392.

Lander, F. P. L. and Davidson, M. (1938). Brit. J. Radiol., 11, 65.

Lees, A. W. (1950). Brit. med. J., $2,1138$.

Nicholson, D. P. (1949). Archives of Disease in Childhood, 24, 29.

Oswald, N. C. (1947). Proc. roy. Soc. Med., 40, 736.

Tannenberg. J. and Pinner, M. (1942). J. thorac. Surg., 11, 571. 